\title{
HSVtk/GCV system on hepatoma carcinoma cells: Construction of the plasmid pcDNA3.1-pAFP-TK and targeted killing effect
}

\author{
YONG-FANG LI $^{1}$, YANG-YANG YUAN ${ }^{1}$, YING-MIN ZHANG ${ }^{1}$, NA ZHAO $^{1}$, QI ZHANG $^{1}$, \\ FAN-XIU MENG ${ }^{1}$, RAN-PENG GAO ${ }^{1}$, BAO-FENG YU ${ }^{1}$, YUE-HONG ZHANG ${ }^{1}$, RUI GUO ${ }^{1}$,

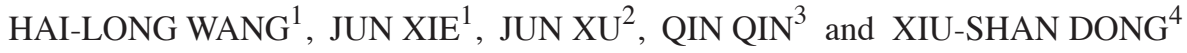 \\ ${ }^{1}$ Department of Biochemistry and Molecular Biology, Shanxi Medical University, Taiyuan, Shanxi 030001; \\ ${ }^{2}$ Department of General Surgery, Affiliated Tumor Hospital of Shanxi Medical University, Taiyuan, Shanxi 030013; \\ ${ }^{3}$ Central Laboratory, Shanxi Provincial People's Hospital, Shanxi Medical University, Taiyuan, Shanxi 030012; \\ ${ }^{4}$ Department of General Surgery, Shanxi Dayi Hospital, Taiyuan, Shanxi 030032, P.R. China
}

Received April 5, 2016; Accepted March 17, 2017

DOI: $10.3892 / \mathrm{mmr} .2017 .6657$

\begin{abstract}
Previous studies demonstrated that herpes simplex virus thymidine kinase (HSVtk) could phosphorylate non-toxic gancyclovir (GCV) efficiently to produce phosphorylated products that result in cell apoptosis, to kill tumor cells. The present study aimed to construct a plasmid vector, pcDNA3.1-pAFP-TK, carrying the suicide gene driven by the alpha-fetoprotein (AFP) promoter, to investigate the cytotoxicity of HSVtk/GCV suicide gene system on hepatoma carcinoma cells. Reverse transcription-polymerase chain reaction and western blotting results demonstrated that the HSVtk gene was effectively expressed in HepG2 hepatoma carcinoma cells transfected with pcDNA3.1-pAFP-TK plasmid, whereas HSVtk gene expression was not detected in normal HL-7702 liver cells. In addition, MTT assays indicated that cell viability of HepG2 cells with the plasmid pcDNA3.1-pAFP-TK decreased in a dose-dependent manner following treatment with GCV for $48 \mathrm{~h}$. Flow cytometry also revealed that the cell apoptosis rate and mitochondrial membrane potential reduction rate in the HepG2 cells treated with HSVtk/GCV suicide gene system were significantly higher than in the control group. Apoptosis rates in the control group and the pcDNA3.1-pAFP-TK group were $(1.00 \pm 0.62 \%)$ and $(38.70 \pm 6.03 \%)$, respectively. Mitochondrial membrane potential reduction rates in the control group and the pcDNA3.1-pAFP-TK group were $(0.57 \pm 0.11 \%)$
\end{abstract}

Correspondence to: Dr Bao-Feng Yu, Department of Biochemistry and Molecular Biology, Shanxi Medical University, 56 Xinjian South Road, Yingze Street, Taiyuan, Shanxi 030001, P.R. China

E-mail: shanxiyangcheng@126.com

Dr Jun Xu, Department of General Surgery, Affiliated Tumor Hospital of Shanxi Medical University, 3 New Worker Village, Apricot Ridge, Taiyuan, Shanxi 030013, P.R. China

E-mail: junxuty@163.com

Key words: AFP promoter, gene therapy, hepatoma carcinoma cells, thymidine kinase, ganciclovir and $(22.84 \pm 5.79 \%)$, respectively. Caspase-3 staining demonstrated that activated caspase- 3 increased significantly in the HepG2 cells treated with HSVtk/GCV suicide gene system, whereas in the control group activated caspase-3 increase was not observed. The results of the present study, therefore, indicated that HSVtk suicide gene was obviously expressed in the HepG2 cells and that the HSVtk/GCV system was effective at killing HepG2 hepatoma carcinoma cells.

\section{Introduction}

Hepatocellular carcinoma (HCC), one of the most frequently diagnosed malignancies in the world, particularly in several areas of Asia and Africa, is the third largest cause of cancer-related death worldwide. Development of HCC is often associated with chronic liver disease, particularly cirrhosis caused by hepatitis B virus (HBV) or hepatitis C virus (HCV). Imaging techniques have detected $\mathrm{HCC}$ at an early stage in patients with chronic HBV or HCV infection (1-4). Early detection of HCC is rare, whereas very few candidates are eligible for liver transplantation as a result of the lack of liver donors (5); thus, recurrence rates of HCC are very high following medical or surgical treatments $(6,7)$. Therefore, the development of an effective targeted gene therapy strategy driven by the tumor-specific promoter has become an urgent requirement in treating $\operatorname{HCC}(8,9)$.

In recent years, gene therapy has been widely studied. The aim of gene therapy is to transfect a target gene into host cells to be specifically expressed, thus killing tumor cells. Currently, suicide gene therapy has become a promising strategy for gene therapy, especially the herpes simplex virus thymidine kinase (HSVtk)/ganciclovir (GCV) system (10). Previous studies have demonstrated the use of a pro-drug sensitive gene as a suicide gene, to convert a non-toxic pro-drug into a toxic product, to block the extension of DNA chains and inhibit the activation of DNA polymerase, finally leading to cell apoptosis (11-13).

At present, a variety of tumor-specific promoters have been used for HCC gene therapy, and the alpha-fetoprotein (AFP) promoter has become an ideal target (14). The regulatory 
regions and sequence of the AFP gene not only specifically activate transcription of exogenous genes but also have significant effects on tumor-specific transcriptional activity (15). Furthermore, in clinical application, AFP gene has been used as a specific marker of HCC.

Therefore, the purpose of the present study was to construct a plasmid, pcDNA3.1-pAFP-TK, to express thymidine kinase (TK) driven by the AFP promoter, to study the selective killing effect on HCC cells.

\section{Materials and methods}

Cell lines and culture. HL-7702 human liver cell line and HepG2 human HCC cell line were purchased from Shanghai Cell Bank of Chinese Academy of Science (Shanghai, China). HeLa human cervical cancer cells were purchased from Basic Medical Cell Bank of Chinese Peking Union Medical University (Beijing, China). HL-7702 cells were maintained in Iscove's modified Dulbecco's medium (IMDM; Hyclone; GE Healthcare Life Sciences, Logan, UT, USA) supplemented with $10 \%$ fetal bovine serum (FBS; Thermo Fisher Scientific, Inc., Waltham, MA, USA), 4 mM L-glutamine, $100 \mathrm{U} / \mathrm{ml}$ penicillin and $100 \mathrm{mg} / \mathrm{ml}$ streptomycin. HeLa and HepG2 cells were cultured in Dulbecco's modified Eagle's medium (DMEM; Hyclone; GE Healthcare Life Sciences) supplemented with $10 \% \mathrm{FBS}, 4 \mathrm{mM}$ L-glutamine, $100 \mathrm{U} / \mathrm{ml}$ penicillin and $100 \mathrm{mg} / \mathrm{ml}$ streptomycin. All cells were maintained at $37^{\circ} \mathrm{C}$ in a humidified atmosphere containing $5 \% \mathrm{CO}_{2}$.

Construction of the plasmid pcDNA3.1-pAFP-TK and bacterial transformation. The pcDNA3.1-pAFP-TK plasmid (Fig. 1) was synthesized by BioVector, Inc. (Beijing, China). Chemically competent Escherichia coli DH5 $\alpha$ cells were purchased from Beijing Solarbio Science \& Technology Co., Ltd. (Beijing, China). Cells $(50 \mu \mathrm{l})$ were thawed on ice, then $5 \mathrm{ng}$ of plasmid DNA was added, mixed gently, and the mixture incubated on ice for $30 \mathrm{~min}$. Cells were then transferred to a $42^{\circ} \mathrm{C}$ water bath for $90 \mathrm{sec}$, then placed on ice for a further 2 min. Sterile lysogeny broth (LB; $400 \mu$; Beijing Solarbio Science \& Technology Co., Ltd.) without antibiotic was added, and the mixture was incubated for $3 \mathrm{~h}$ at $37^{\circ} \mathrm{C}$ in a shaker at $200 \mathrm{rpm} / \mathrm{min}$ to recover the cells. The mixture was then centrifuged at $1,006.2 \times \mathrm{g}$ for $3 \mathrm{~min}$ at $4^{\circ} \mathrm{C}$, the supernatant was discarded, and the pellet was resuspended in $100 \mu \mathrm{LB}$. Cells were plated on solid LB containing agar and $50 \mathrm{mg} / \mathrm{ml}$ ampicillin (Sangon Biotech Co., Ltd., Shanghai, China) and incubated at $37^{\circ} \mathrm{C}$ for $12-16 \mathrm{~h}$. Single colonies were then picked into $100 \mathrm{ml} \mathrm{LB}$ and incubated at $37^{\circ} \mathrm{C}$ for $16 \mathrm{~h}$ in a shaker at $260 \mathrm{rpm} / \mathrm{min}$.

Extraction and identification of the pcDNA3.1-pAFP-TK plasmid. Plasmid extraction kit was purchased from Sangon Biotech Co., Ltd. and pcDNA3.1-pAFP-TK plasmid DNA was extracted from E.coli DH5 $\alpha$ according to the manufacturer's protocol. Plasmid DNA was digested with XhoI and BamHI and the products were visualized under UV transillumination following separation on a $1 \%$ agarose gel stained with fluorescence staining dye Goldviewna I (Beijing Solarbio Science \& Technology Co., Ltd.), using the DNA marker DM 2000 Plus (CWBio, Beijing, China). DNA fragments were subsequently sequenced by BioVector, Inc., and Basic Local Alignment Search Tool (BLAST; National Center for Biotechnology Information, National Institutes of Health, Bethesda, MD, USA) was used to analyze the homology of the HSVtk gene and plasmid DNA sequences.

Cell transfection. HL-7702, HeLa and HepG2 cells were transfected with Lipofectamine 2000 Reagent (Invitrogen; Thermo Fisher Scientific, Inc.) according to the manufacturer's protocols. For MTT assays, HepG2 cells were cultured to the exponential phase of growth and then were seeded in 96 well plates at a density of $10^{4}$ cells per well. For flow cytometry, HepG2 cells were incubated in 6 well plates at a density of $5 \times 10^{5}$ cells per well. For the transfection experiments, cells were divided into the pcDNA3.1-pAFP-TK group and the control group and were incubated overnight in $5 \% \mathrm{CO}_{2}$ at $37^{\circ} \mathrm{C}$. Cells in the control group received no treatment. The following day, cells in the pcDNA3.1-pAFP-TK group were washed twice with PBS and fresh serum-free DMEM was added to each well. Transfection was conducted with $7 \mu$ l Lipofectamine 2000 and $2.5 \mu \mathrm{g}$ plasmid DNA. Following $6 \mathrm{~h}$ incubation in $5 \% \mathrm{CO}_{2}$ at $37^{\circ} \mathrm{C}$, the cell medium was replaced with medium containing $10 \% \mathrm{FBS}$ and the cells were incubated for a further $48 \mathrm{~h}$ an additional culture of $48 \mathrm{~h}$.

Reverse transcription-polymerase chain reaction (RT-PCR). mRNA expression of $H S V t k$ was analyzed by RT-PCR. HL-7702, HeLa and HepG2 cells were transfected withcDNA3.1-pAFP-TK, then total RNA was extracted using TRIzol ${ }^{\circledR}$ reagent (Thermo Fisher Scientific, Inc.). cDNA was reverse transcribed from the total RNA according to the manufacturer's protocol, using dNTP Mix, 5X RT buffer, HiFiScript 1st Strand cDNA Synthesis kit and RNase-free water (CWBio). PCR was then performed, using Goldviewna I (Beijing Solarbio Science \& Technology Co., Ltd.) as the fluorophore, to amplify TK, with $\beta$-actin as an internal control, using the following primer sequences: TK, forward 5'-CAACAAAAAGCCACG GAAGT-3' and reverse 5'-ATGCTGCCCATAAGGTATCG-3'; and $\beta$-actin, forward 5'-TGACGTGGACATCCGCAAAG-3' and reverse 5'-CTGGAAGGTGGACAGCGAGG-3'. The amplification products of TK and $\beta$-actin were, respectively, 446 and $205 \mathrm{bp}$ in length. PCR was performed using the following DNA thermal cycler conditions: 1 cycle of $94^{\circ} \mathrm{C}$ for $2 \mathrm{~min}$; 30 cycles of $94^{\circ} \mathrm{C}$ for $30 \mathrm{sec}, 55^{\circ} \mathrm{C}$ for $30 \mathrm{sec}, 72^{\circ} \mathrm{C}$ for $1 \mathrm{~min}$; and a final elongation step of $72^{\circ} \mathrm{C}$ for $5 \mathrm{~min}$. The PCR products were visualized under UV transillumination following separation by $1 \%$ agarose gel electrophoresis stained with fluorescence staining dye Goldviewna I alongside a DNA marker (Takara Biotechnology Co., Ltd., Dalian, China).

Western blot. HL-7702, HeLa and HepG2 cells were treated as described. Total protein was extracted following transfection using a radioimmunoprecipitation assay lysis buffer (Beyotime Institute of Biotechnology, Haimen, China) at $4^{\circ} \mathrm{C}$ for $30 \mathrm{~min}$, and the lysates were centrifuged at $4^{\circ} \mathrm{C}$ for $20 \mathrm{~min}$ at $4,360.2 \mathrm{x}$ g. Protein concentration in cell lysates was determined using a bicinchoninic acid protein assay kit (Boster Systems, Inc., Pleasanton, CA, USA). Proteins were then separated by 5-12\% SDS-PAGE, transferred onto polyvinylidene fluoride membranes, and blocked by incubation in $5 \%$ skim milk in 
TBS containing $0.05 \%$ Tween-20 at room temperature for $2 \mathrm{~h}$. Membranes were then incubated overnight at $4^{\circ} \mathrm{C}$ with goat polyclonal anti-HSVtk (1:800; cat no. sc-28038; Santa Cruz Biotechnology, Inc., Dallas, TX, USA) and anti- $\beta$-actin (1:800; cat no. TA-09; ZSGB-BIO, Beijing, China) primary antibodies, washed in TBS containing $0.1 \%$ Tween-20 (TBST) for 3x10 min, incubated at $4^{\circ} \mathrm{C}$ for $1 \mathrm{~h}$ with horseradish peroxidase-conjugated secondary antibody (1:5,000; cat no. A0181; Beyotime Institute of Biotechnology), then the membranes washed again in TBST for 3x10 min. Finally, the expression of HSVtk and $\beta$-actin was visualized using enhanced chemiluminescence (Wuhan Boster Biological Technology, Ltd., Wuhan, China).

MTT assay. HepG2 cells transfected with pcDNA3.1-pAFP-TK (100 $\mu 1$ transfected cells) were seeded in 96-well plates at a density of $10^{4}$ cells per well and incubated overnight at $37^{\circ} \mathrm{C}$ in a humidified atmosphere containing $5 \% \mathrm{CO}_{2}$. Cells were then treated with $0,1,5,10,20,40,60$ or $80 \mu \mathrm{g}$ GCV and incubated in $5 \% \mathrm{CO}_{2}$ at $37^{\circ} \mathrm{C}$. After 4 days, cells were observed under the microscope. MTT substrate $(20 \mu \mathrm{l})$ was added to each well and the plates were incubated in $5 \% \mathrm{CO}_{2}$ at $37^{\circ} \mathrm{C}$ for a further $4 \mathrm{~h}$. The medium was then discarded and $150 \mu \mathrm{l}$ DMSO were added to each well at room temperature for $10 \mathrm{~min}$. A microplate reader was used to measure the absorbance at $490 \mathrm{~nm}$ $\left(\mathrm{A}_{490}\right)$, and the inhibition rate was calculated as: [1- $\left(\mathrm{A}_{490}\right.$ of pcDNA3.1-pAFP-TK group/ $\mathrm{A}_{490}$ of the control group)]x100\%.

Detection of cell apoptosis by flow cytometry. Cell apoptosis was detected with an Annexin V-fluorescein isothiocyanate (FITC)/propidium iodide (PI) apoptosis detection kit (Invitrogen; Thermo Fisher Scientific, Inc.). pcDNA3.1-pAFP-TK was transfected into HepG2 cells. Cells in the control group received no transfection and no further treatments. Following $48 \mathrm{~h}$ incubation, the pcDNA3.1-pAFP-TK group was treated with $150 \mu \mathrm{g} / \mathrm{ml} \mathrm{GCV}$ for 2 days. Cells were harvested with $0.25 \%$ trypsin then sedimented by centrifugation at $335.4 \mathrm{x} \mathrm{g}$ for $3 \mathrm{~min}$ at room temperature. The supernatant was then discarded, cells were washed twice with PBS, then $100 \mu$ l binding buffer (Nanjing KeyGen Biotech Co., Ltd., Nanjing, China) was added to resuspend the cells. Cell suspension $(100 \mu \mathrm{l})$ was then added to the flow tube, along with $5 \mu \mathrm{l}$ Annexin V-FITC at a final concentration of $1 \mu \mathrm{g} / \mathrm{ml}$ and $10 \mu \mathrm{l}(250 \mathrm{ng})$ of PI. The cells were mixed and incubated for $15 \mathrm{~min}$ at room temperature in the dark. Finally, $400 \mu \mathrm{l}$ binding buffer was added and flow cytometry was used to detect cell apoptosis, using the BD FACSCalibur ${ }^{\mathrm{TM}}$ flow cytometer and the BD FACStation ${ }^{\mathrm{TM}}$ software (BD Biosciences, Franklin Lakes, NJ, USA).

Detection of mitochondrial membrane potential by flow cytometry. The mitochondrial membrane potential apoptosis detection kit was purchased from Beijing ComWin Company (Beijing, China). HepG2 cells were transfected with pcDNA3.1-pAFP-TK, whereas the control group received no intervention. Following $48 \mathrm{~h}$ incubation, the pcDNA3.1-pAFP-TK group was treated with $150 \mu \mathrm{g} / \mathrm{ml} \mathrm{GCV}$ for 2 days. The culture media was then discarded, the cells were washed once with PBS, then $1 \mathrm{ml}$ cell culture medium and $1 \mathrm{ml} \mathrm{JC}-1$ staining solution was added and the cells were incubated in a cell culture incubator at $37^{\circ} \mathrm{C}$ for $20 \mathrm{~min}$. The supernatant was then removed and the cells were washed

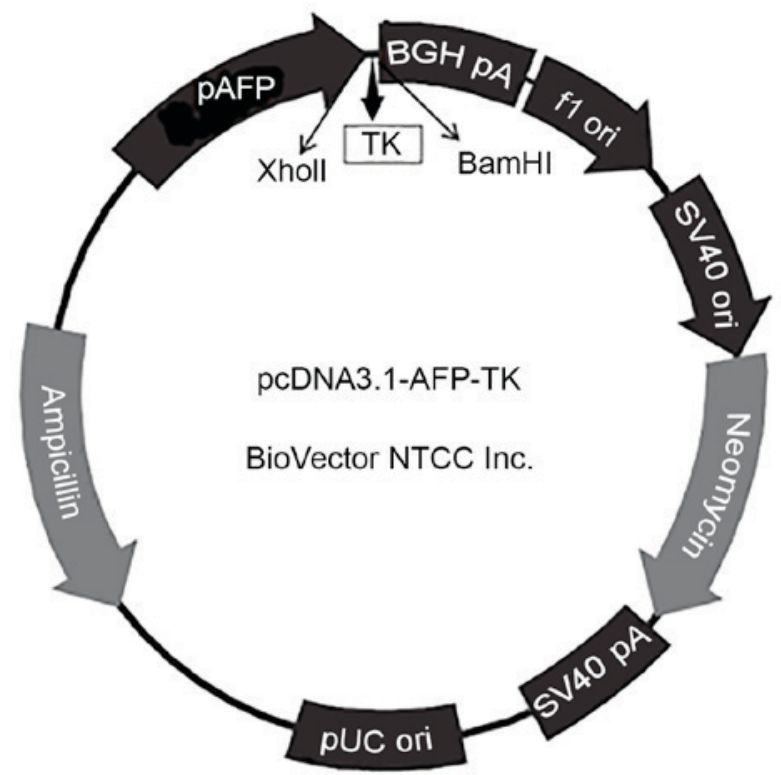

Figure 1. Plasmid map of pcDNA3.1-pAFP-TK. TK, thymidine kinase; pAFP, alpha-fetoprotein-producing promoter.

twice with 1X JC-1 staining buffer (Abcam, Cambridge UK). Finally, $2 \mathrm{ml}$ of cell culture medium was added to the cells and fluorescence was observed under a fluorescence microscope, to reflect cell apoptosis. Three slides were observed and $>10$ fields of view/slide were assessed.

Detection of activated caspase-3 by caspase-3 staining. The Active Caspase-3 Staining kit was purchased from BioVision, Inc.(Milpitas, CA, USA). HepG2 cells in 6 well plates were transfected with pcDNA3.1-pAFP-TK using Lipofectamine2000 (Invitrogen; Thermo Fisher Scientific, Inc.), alongside an untreated control group. The pcDNA3.1-pAFP-TK group was treated with $150 \mu \mathrm{g} / \mathrm{ml} \mathrm{GCV}$ for $48 \mathrm{~h}$, then all the cells were collected by centrifugation at $4^{\circ} \mathrm{C}$ at $335.4 \mathrm{x}$ g for $3 \mathrm{~min}$. Cells were then resuspended in $300 \mu \mathrm{l}$ cell culture medium with $1 \mu \mathrm{l}$ Red-DEVD-FMK and incubated for $1 \mathrm{~h}$ at $37^{\circ} \mathrm{C}$ with $5 \% \mathrm{CO}_{2}$. Cells were then centrifuged at $335.4 \mathrm{x}$ g for $3 \mathrm{~min}$, the supernatant was discarded, and cells were resuspended in $100 \mu \mathrm{l}$ water buffer provided in the kit. Finally, a drop of the cell suspension was placed onto a microslide and covered with a coverslip. Red fluorescence was observed under a fluorescence microscope, to evaluate the levels of activated caspase-3. Three slides were observed and $>10$ fields of view/slide were assessed.

Statistical analysis. Data was expressed as the mean \pm standard deviation, and all assays were performed in triplicate. Statistical differences were evaluated by Student's t-test using SPSS 16.0 software (SPSS Inc., Chicago, IL, USA). P<0.05 was considered to indicate a statistically significant difference.

\section{Results}

Detection of the pcDNA3.1-pAFP-TK plasmid. Following digestion of pcDNA3.1-pAFP-TK was digested with XholI and BamHI, a 1131-bp fragment was detected by agarose gel electrophoresis (Fig. 2), which demonstrated that the HSVtk gene was successfully inserted into the plasmid pcDNA3.1-pAFP-TK. 


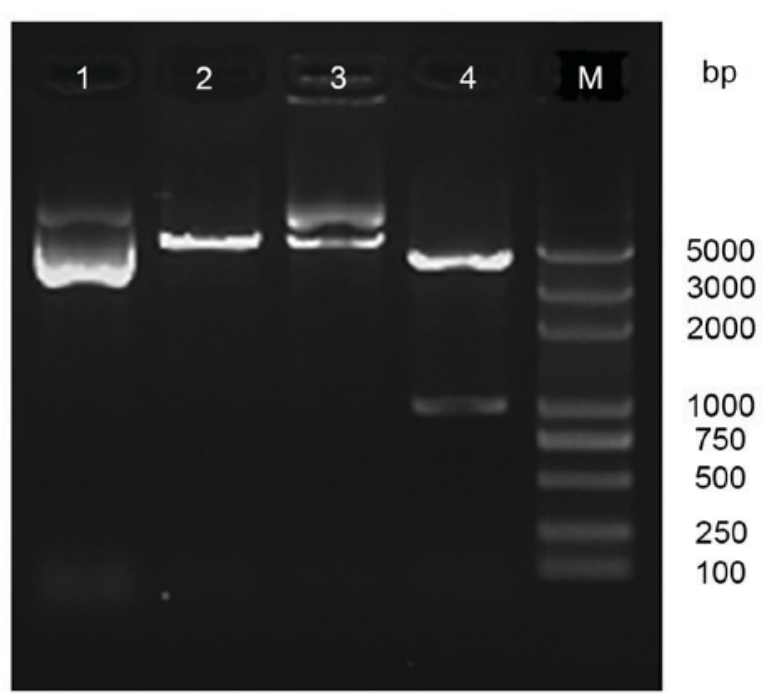

Figure 2. Identification of the plasmid pcDNA3.1-pAFP-TK by restriction enzyme digestion. Lane 1, pcDNA3.1-pAFP-TK; Lane 2, Xholl single digest; Lane 3, BamHI single digest; Lane 4: XholI and BamHI double digest; Marker, DM 2000 Plus.

Sequence analysis of pcDNA3.1-pAFP-TK by BLAST. DNA sequencing demonstrated that the construction of the plasmid pcDNA3.1-pAFP-TK was successful and that the pcDNA3.1-pAFP-TK vector had a 1131-bp fragment (Fig. 3A). This fragment was confirmed to be an insertion of the HSVtk gene by BLAST (Fig. 3B).

Detection of HSVtk mRNA expression. RT-PCR was used to analyze the expression of HSVtk mRNA in the HL-7702 cells, the HeLa cells and the HepG2 cells. As demonstrated in Fig. 4, a 446 bp product was observed in HepG2 cells transfected with the plasmid pcDNA3.1-pAFP-TK, but no product was observed in HL-7702 cells or HeLa cells. Therefore, the result indicated that the expression of HSVtk gene mRNA had a high level in the HepG2 cells.

HSVtk suicide gene protein expression. The expression of $H S V t k$ protein was demonstrated by western blotting. A $36 \mathrm{kDa}$ protein band was detected in the HepG2 cells transfected with pcDNA3.1-pAFP-TK, but no expression was observed in HL-7702 cells or HeLa cells (Fig. 5). The result suggested that $H S V t k$ was highly expressed in HepG2 cells.

Cell viability assay. MTT assays were performed to investigate cell viability in theHepG2 cells interfered by the HSVtk/GCV suicide gene system. With high levels of GCV, transfected cells were killed and the cell morphology was altered compared with untransfected and untreated cells (Fig. 6). As demonstrated by the GCV dose-response curve (Table I and Fig. 7), cell viability in the pcDNA3.1-pAFP-TK group gradually reduced compared with the control group as GCV concentration increased.

Detection of apoptosis by flow cytometry. As demonstrated in Fig. 8, the apoptosis rate in the pcDNA3.1-pAFP-TK group $(38.70 \pm 6.03 \%)$ was significantly higher than the apoptosis rate in the control group $(1.00 \pm 0.62 \% ; \mathrm{P}<0.001)$. 

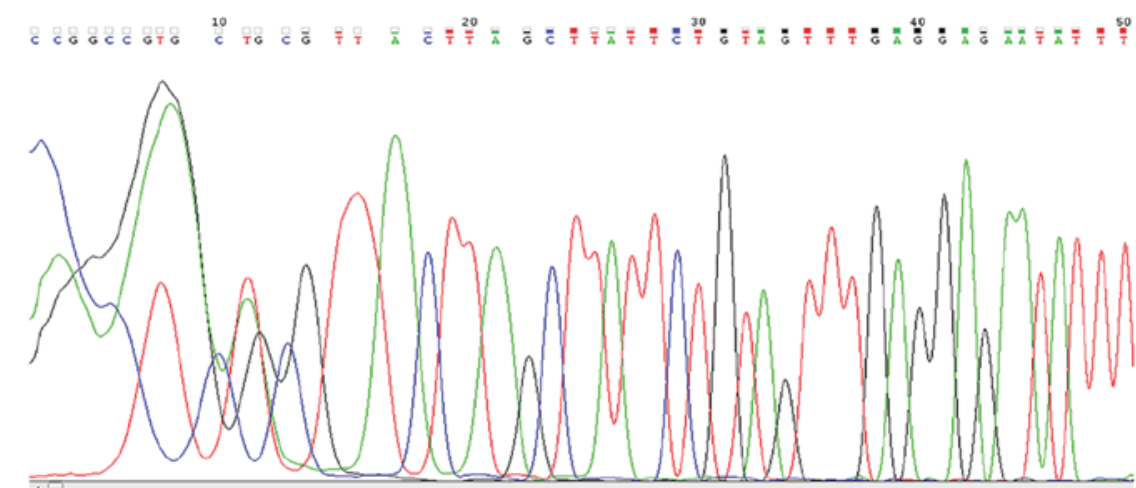

B Human herpesvirus 1 strain $9 / 3$ thymidine kinase (UL23) gene, complete cds Sequence ID: gb|AY575228.1 Length: 1131 Number of Matches: 1

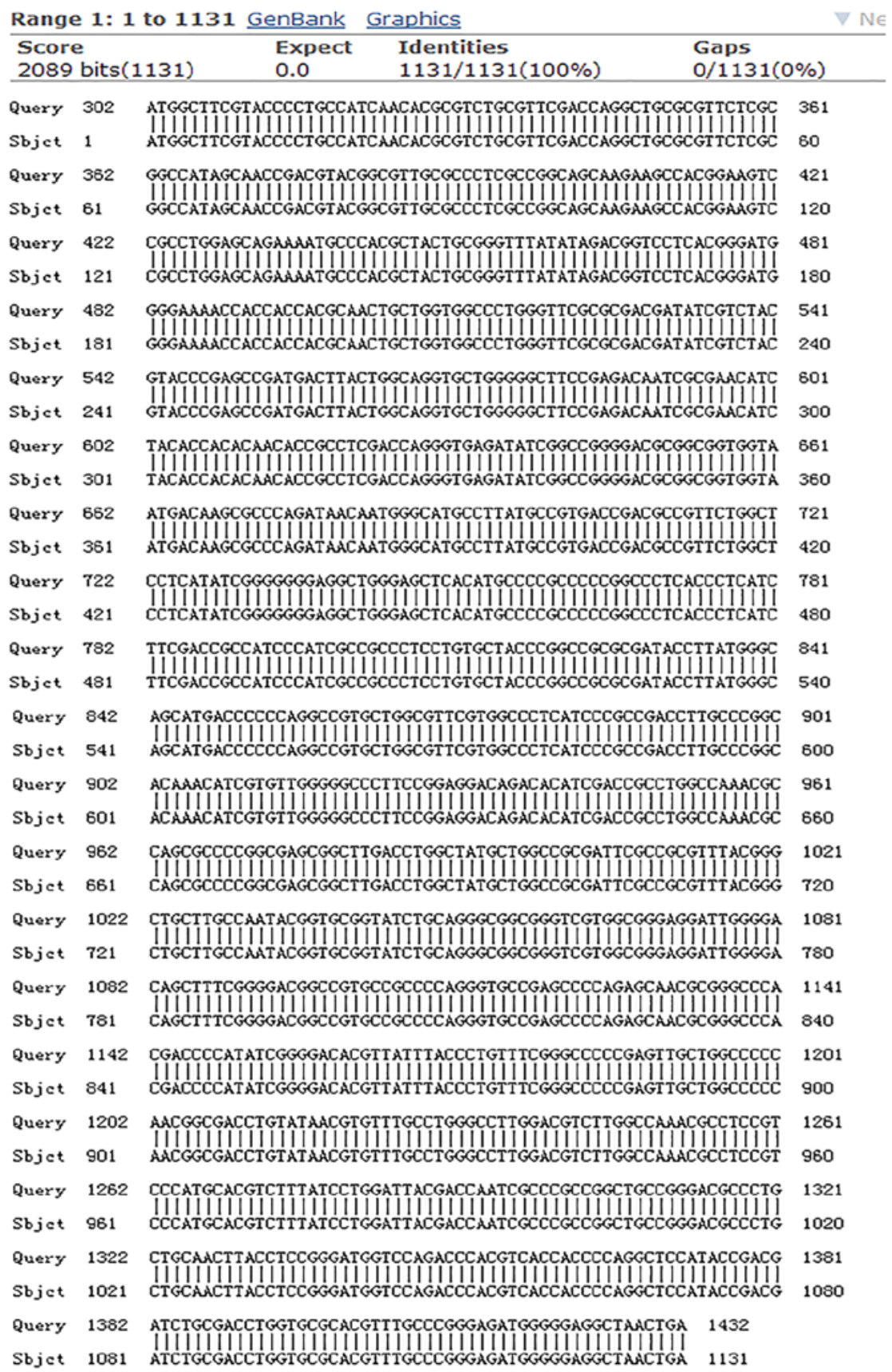

Figure 3. The result of the plasmid pcDNA3.1-pAFP-TK sequencing. (A) The pcDNA3.1-pAFP-TK plasmid fragment following DNA sequencing. (B) Analysis of fragment homology of DNA sequences by Basic Local Alignment Search Tool. Subject sequence, 1,131-bp fragment of the pcDNA3.1-pAFP-TK plasmid, confirmed as the insertion of the HSVtk gene; query sequence, HSVtk gene. 
A

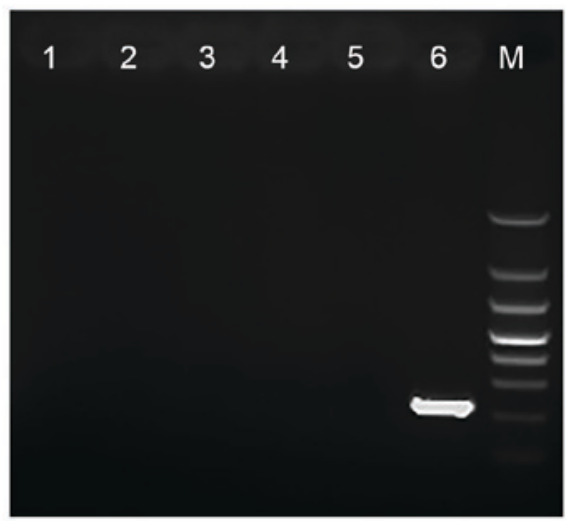

B

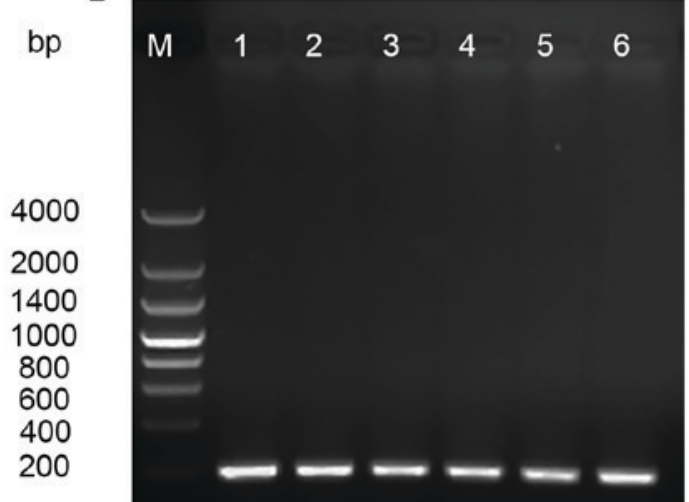

Figure 4. Expression of HSVtk mRNA examined by reverse transcription polymerase chain reaction. (A) Expression of the 446 bp $H S V t k$ gene and (B) the 205 bp $\beta$-actin gene. Lane 1, HL-7702; Lane 2, HL-7702/pcDNA3.1-pAFP-TK; Lane 3, HeLa; Lane 4, HeLa/pcDNA3.1-pAFP-TK; Lane 5, HepG2; Lane 6, HepG2/pcDNA3.1-pAFP-TK; Marker, 200 bp ladder.

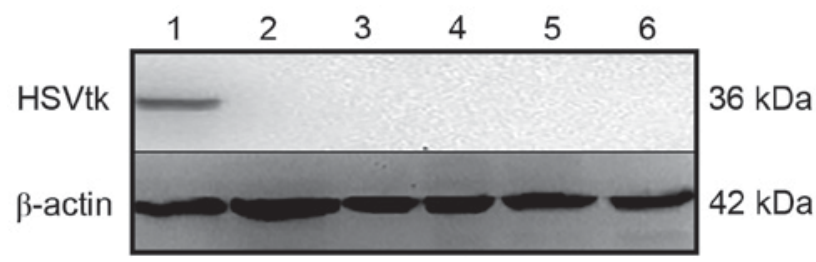

Figure 5. Expression of HSVtk protein expression examined by western blotting. Lane 1, HepG2/pcDNA3.1-pAFP-TK; Lane 2, HepG2; Lane 3, HeLa/pcDNA3.1-pAFP-TK; Lane 4, HeLa; Lane 5, HL-7702/pcDNA3.1-pAFP-TK; Lane 6: HL-7702.
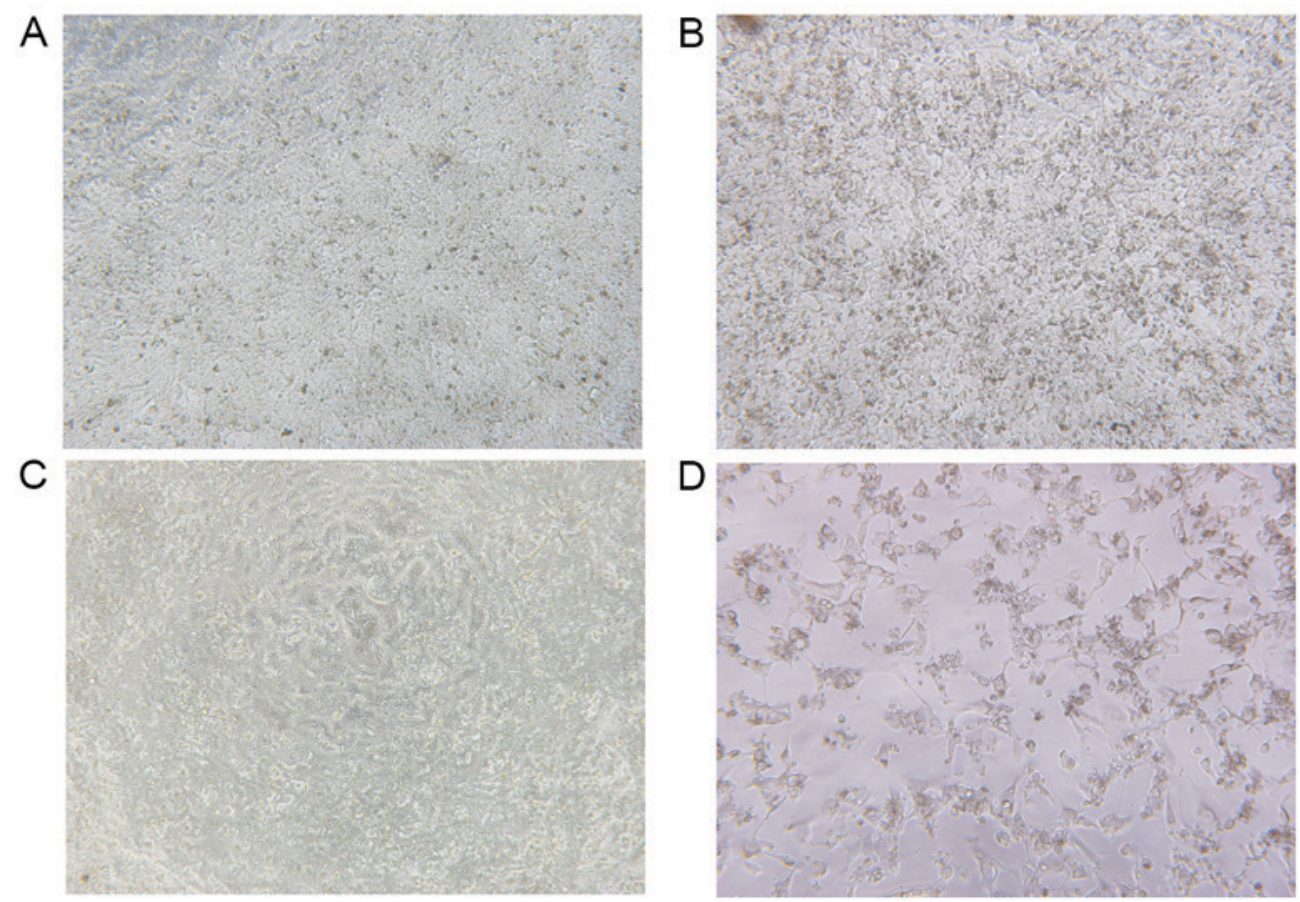

Figure 6. Cell morphology in the untransfected control group and pcDNA3.1-pAFP-TK (original magnification, x100). (A) Control with $0 \mu \mathrm{g}$ GCV; (B) Control with $80 \mu \mathrm{g} \mathrm{GCV}$; (C) pcDNA3.1-pAFP-TK group with $0 \mu \mathrm{g} \mathrm{GCV}$; (D) pcDNA3.1-pAFP-TK group with $80 \mu \mathrm{g}$ GCV. GCV, gancyclovir.

Detection of mitochondrial membrane potential by flow cytometry. As demonstrated in Fig. 9, the mitochondrial membrane potential reduction rate in the pcDNA3.1-pAFP-TK group $(22.84 \pm 5.79 \%)$ was significantly higher than the rate in the control group $(0.57 \pm 0.11 ; \mathrm{P}<0.01)$.
Detection of activated caspase-3 by fluorescence microscopy. Caspase-3 staining was used to detect activated caspase-3 in the HepG2 cells. The results demonstrated that compared with control cells (Fig. 10A), HepG2 cells interfered with HSVtk/GCV suicide gene system emitted a brighter red 


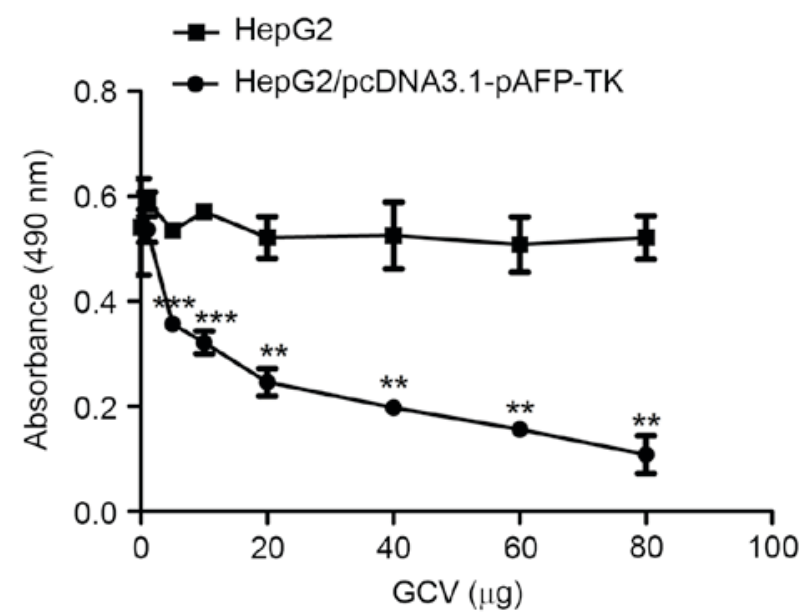

Figure 7. Cell viability in the control group and pcDNA3.1-pAFP-TK group, in response to GCV. Significant growth inhibition was observed in the pcDNA3.1-pAFP-TK group compared with the control group. ${ }^{* *} \mathrm{P}<0.01$ and ${ }^{* * * *} \mathrm{P}<0.001$ vs. control group ( $\mathrm{n}=3$ ). GCV, gancyclovir.
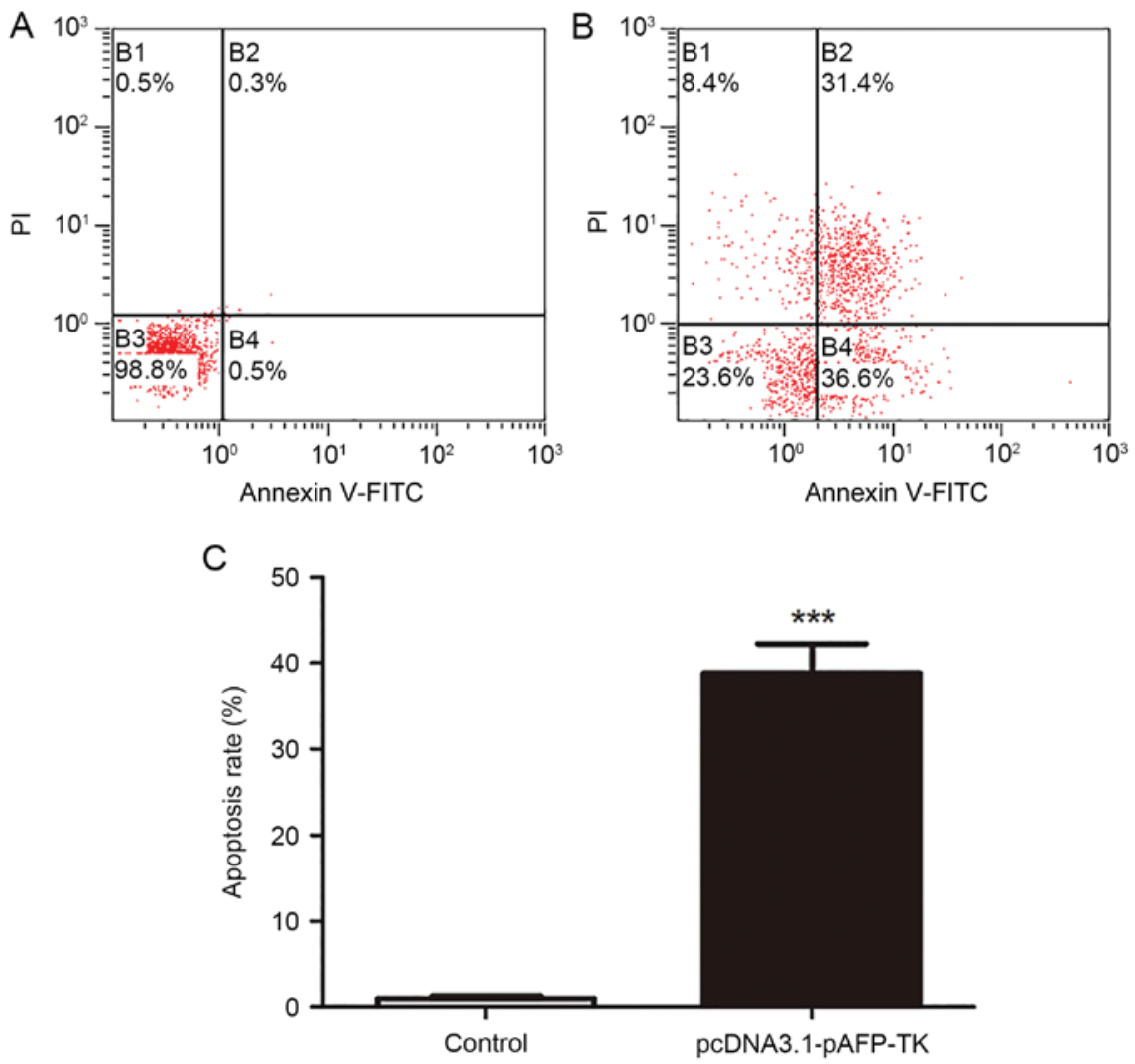

Figure 8. Detection of HepG2 cell apoptosis by flow cytometry in the (A) control group and (B) pcDNA3.1-pAFP-TK group. (C) Comparison of apoptosis rates between the pcDNA3.1-pAFP-TK group and the control group. ${ }^{* * *} \mathrm{P}<0.001$ vs. control group $(\mathrm{n}=3)$. PI, propidium iodide; FITC, fluorescein isothiocyanate.

signal (Fig. 10B), indicating increased levels of activated caspase-3. Activated caspase-3 played an important role in the early stage apoptotic cells, therefore, HSVtk/GCV suicide gene system had a significant killing effect on the HepG2 cells.

\section{Discussion}

The worldwide incidence and mortality rates of HCC appear to be increasing year by year, the incidence of which ranked the fifth among all cancer cases (16). HCC represents the third leading cause of cancer-associated mortality worldwide $(17,18)$. Based on the cellular and molecular levels, targeted therapy for combining drugs with the specific target could kill tumor cells, but rarely threatened normal tissues and cells. Gene therapy aims to insert exogenous normal genes into target cells to compensate for genetic defects and disease-related abnormalities. The combination of targeted therapy with gene therapy acts as a powerful target gene for killing human hepatoma carcinoma cells. 

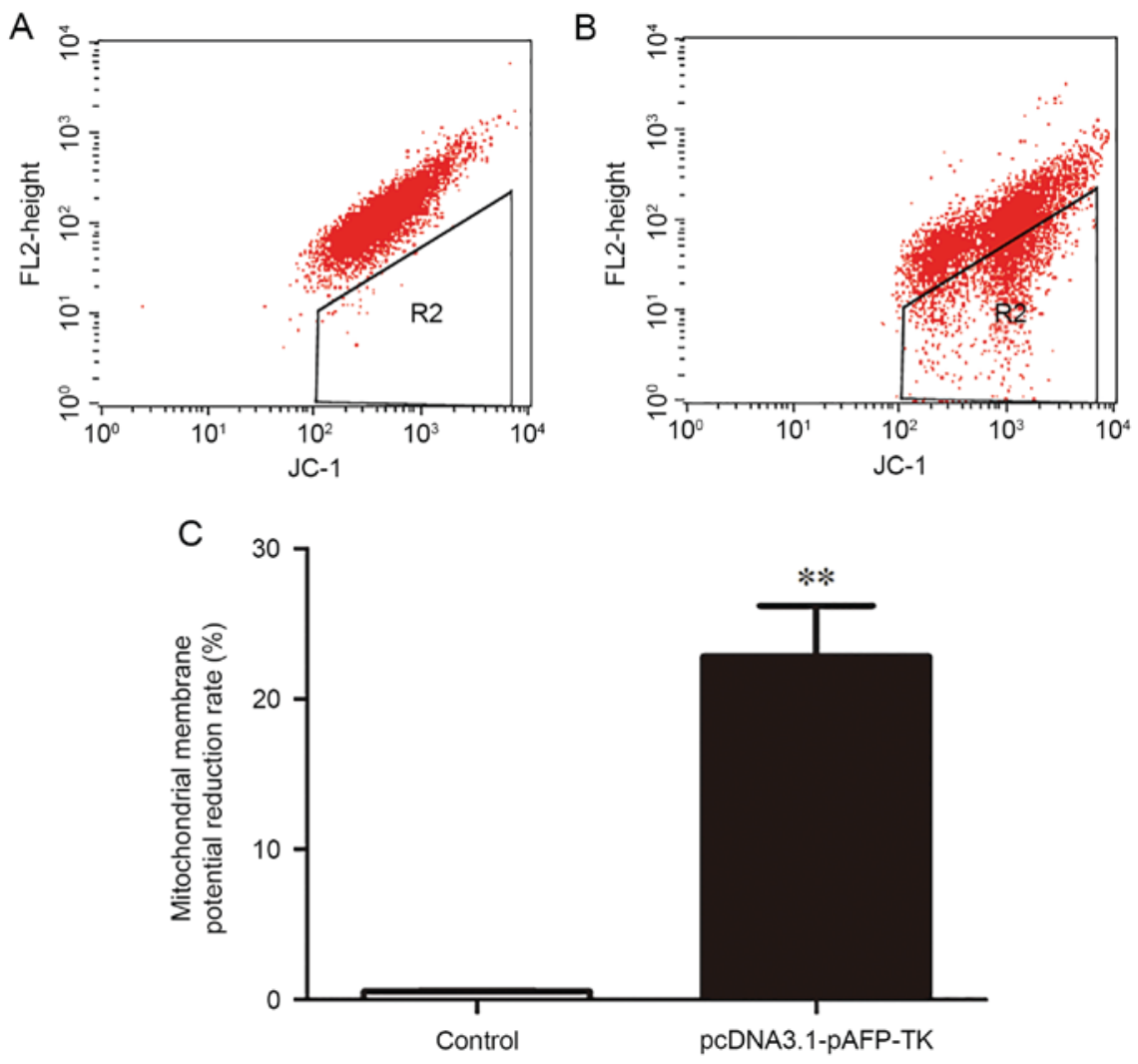

Figure 9. Flow cytometric detection of HepG2 cell mitochondrial membrane potential in the (A) control group and (B) pcDNA3.1-pAFP-TK group (C) Comparison of rate of reduction of mitochondrial membrane potential between the pcDNA3.1-pAFP-TK group and the control group. ${ }^{* *} \mathrm{P}<0.01$ vs. control group ( $\mathrm{n}=3)$.
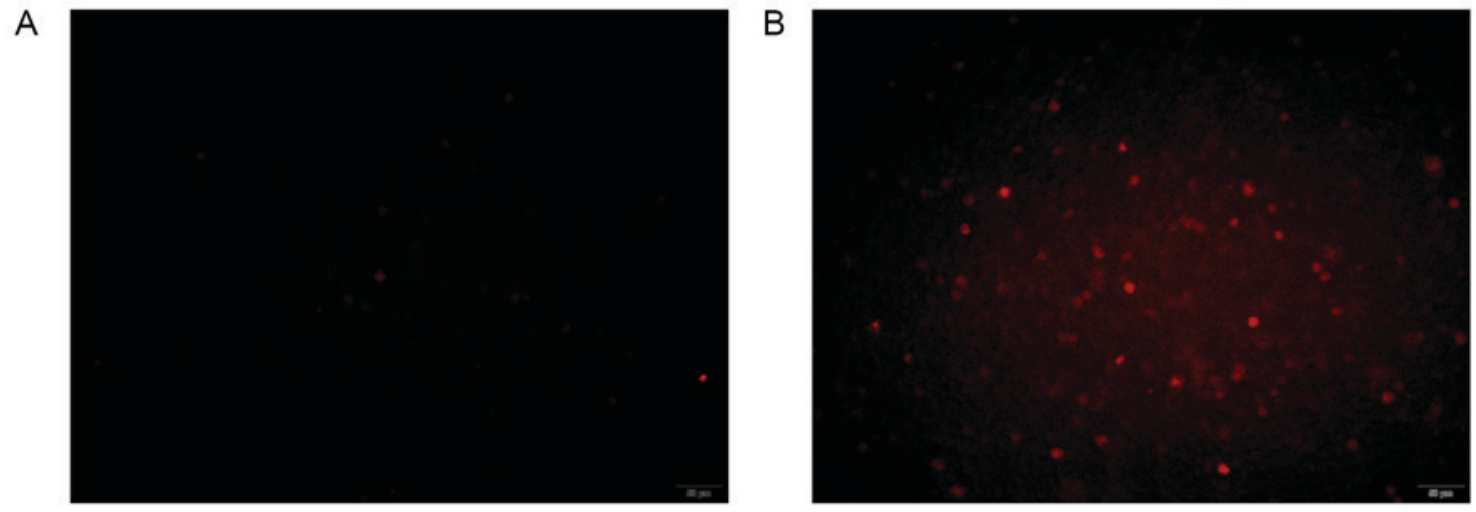

Figure 10. Detection of activated caspase-3 in HepG2 cells by caspase-3 staining (original magnification, x200). (A) Control group and (B) pcDNA3.1-pAFP-TK group.

The two most widely used suicide gene systems are the $\mathrm{CD} / 5-\mathrm{FC}$ system and the HSVtk/GCV system (19). In the $\mathrm{CD} / 5-\mathrm{FC}$ system, the cytosine deaminase gene $(C D)$ of some bacteria and fungi generates the $\mathrm{CD}$ enzyme, which converts cytosine to uracil; non-toxic 5-fluorocytosine is transformed into cytotoxic 5-fluorouracil (5-FU), thereby killing tumor cells (20). HSVtk efficiently phosphorylates non-toxic gancyclovir (GCV) to produce phosphorylated products that lead to an arrest of DNA synthesis and cell death $(21,22)$. However, normal cells could be killed as a result of lack of specific suicide gene, therefore, improved efficiency of targeted gene therapy is essential. It was, therefore, imperative to construct a novel recombinant vector, to be transfected into tumor cells with a targeted ability to kill cells. Previous studies have demonstrated that some biochemical markers were tied to hepatoma carcinoma cells, such as AFP, vascular endothelial growth factor (VEGF) $(23,24)$.

AFP is a major serum protein produced by fetal hepatocytes. It is not detectable in normal adult cells, however, in HCC cells, the AFP gene is highly expressed $(25,26)$. Therefore, AFP sequences could be used to regulate expression of cytotoxic genes, as in the HSVtk/GCV system, through use of the AFP promoter; the system has been reported to have a limited effect on hepatoma cells (27). The HSVtk/GCV system was a successful suicide gene therapy strategy for $\operatorname{HCC}(28,29)$. 
The results of the present study demonstrated that the novel plasmid pcDNA3.1-pAFP-TK, driven by the AFP promoter, was constructed successfully. The plasmid pcDNA3.1-pAFP-TK was transfected into HL-7702, HeLa, and HepG2 cells. RT-PCR and western blot demonstrated that $H S V t k$ was effectively expressed in HepG2 cells transfected with the plasmid pcDNA3.1-pAFP-TK, whereas HSVtk gene expression was not detected in HL-7702 and HeLa cells. Furthermore, MTT assays indicated that, with increasing of GCV doses, the HepG2 cells viability significantly decreased; cell viability was significantly affected in HepG2 cells transfected with pcDNA3.1-pAFP-TK by $5 \mu \mathrm{g} \mathrm{GCV}$, and when GCV was increased to $80 \mu \mathrm{g}$, it was evident that that cell viability was severely suppressed. In addition, flow cytometry demonstrated that in HepG2 cells treated with HSVtk/GCV suicide gene system, cell apoptosis rates and mitochondrial membrane potential reduction rates were increased dramatically in comparison with the control group. Caspase-3 staining demonstrated that activated caspase-3 increased significantly in the HepG2 cells with the HSVtk/GCV suicide gene system, supporting the cell apoptosis results, whereas increased activated caspase-3 was not observed in the control group.

Therefore, the present study has constructed a novel plasmid vector driven by the human AFP promoter, which may has become an effective approach in overcoming the restrictions of current technologies.

\section{Acknowledgements}

The present study was funded by grants from the National Natural Science Foundation of China (grant nos. 30901821 and 81172136) and Natural Science Foundation of Shanxi (grant no. 2015011113).

\section{References}

1. Bosch FX, Ribes J, Diaz M and Cléries R: Primary liver cancer: Worldwide incidence and trends. Gastroenterology 127 (5 Suppl 1): S5-S16, 2004.

2. Levin B and Amos C: Therapy of unresectable hepatocellular carcinoma. N Engl J Med 332: 1294-1296, 1995.

3. Arii S, Yamaoka Y, Futagawa S, Inoue K, Kobayashi K, Kojiro M Makuuchi M, Nakamura Y, Okita K and Yamada R: Results of surgical and nonsurgical treatment for small-sized hepatocellular carcinomas: A retrospective and nationwide survey in Japan. The liver cancer study group of Japan. Hepatology 32: 1224-1229, 2000.

4. Rongrui L, Na H, Zongfang L, Fanpu J and Shiwen J: Epigenetic mechanism involved in the HBV/HCV-related hepatocellular carcinoma tumorigenesis. Curr Pharm Des 20: 1715-1725, 2014.

5. Llovet JM, Di Bisceglie AM, Bruix J, Kramer BS, Lencioni R, Zhu AX, Sherman M, Schwartz M, Lotze M, Talwalkar J, et al: Design and endpoints of clinical trials in hepatocellular carcinoma. J Natl Cancer Inst 100: 698-711, 2008.

6. Cheng AL, Kang YK, Chen Z, Tsao CJ, Qin S, Kim JS, Luo R, Feng J, Ye S, Yang TS, et al: Efficacy and safety of sorafenib in patients in the Asia-Pacific region with advanced hepatocellular carcinoma: A phase III randomised, double-blind, placebo-controlled trial. Lancet Oncol 10: 25-34, 2009.

7. Liver Cancer Study Group of Japan: Primary liver cancer in Japan. Clinicopathologic features and results of surgical treatment. Ann Surg 211: 277-287, 1990.

8. Schmitz V, Qian C, Ruiz J, Sangro B, Melero I, Mazzolini G, Narvaiza I and Prieto J: Gene therapy for liver diseases: Recent strategies for treatment of viral hepatitis and liver malignancies. Gut 50: 130-135, 2002.

9. Dachs GU, Dougheay GJ, Stratford IJ and Chaplin DJ: Targeting gene therapy to cancer: A review. Oncol Ras 9: 313-325, 1997.
10. Ferrara F, Staquicini DI, Driessen WH, D'Angelo S, Dobroff AS, Barry M, Lomo LC, Staquicini FI, Cardó-Vila M, Soghomonyan S, et al: Targeted molecular-genetic imaging and ligand-directed therapy in aggressive variant prostate cancer. Proc Natl Acad Sci USA pii: 201615400, 2016.

11. Anderson WF: Gene therapy for cancer. Hum Gene Ther 5: 1-2, 2008.

12. Huber BE, Richards CA and Krenitsky TA: Retroviral-mediated gene therapy for the treatment of hepatocellular carcinoma: All innovative approach for therapy. Proc Natl Acad Sci USA 88: 8039-8043, 1991

13. Yashiyasu K and Ayumi T: Gene therapy of hepatoma: Bystander effects and non-apoptotic cell death induced by thymidine kinase and ganciclovir. Cancer Lett 96: 105-110, 1995.

14. Ma WJ, Wang HY and Teng LS: Correlation analysis of preoperative serum alpha-fetoprotein (AFP) level and prognosis of hepatocellular carcinoma (HCC) after hepatectomy. World J Surg Oncol 11: 212, 2013

15. Su H, Chang JC, Xu SM and Kan YW: Selective killing of AFP-positive hepatocellular carcinoma cells by adeno-associated virus transfer of the herpes simplex virus thymidine kinase gene. Hum Gene Ther 7: 463-470, 1996.

16. Cahill BA and Braccia D: Current treatment for hepatocellular carcinoma. Clin J Oncol Nurs 8: 393-399, 2004.

17. Farazi PA and DePinho RA: Hepatocellular carcinoma pathogenesis: From genes to environment. Nat Rev Cancer 6: 674-687, 2006.

18. Varela M, Sala M, Llovet JM and Bruix J: Treatment of hepatocellular carcinoma: Is there an optimal strategy. Cancer Treat Rev 29: 99-104, 2003.

19. Huber BE, Austin EA, Richards CA, Davis ST and Good SS: Metabolism of 5-fluorocytidineto5-fluorouracic in human colorectal tumor cells transduced with the cytosine deaminase gene: Significant antitumor effect when only a small percentage of tumor cells express cytosine deaminase. Proc Natl Acad Sci USA 91: 8302-8306, 1994.

20. Yang XP, Liu L, Wang P and Ma SL: Human sulfatase-1 improves the effectiveness of cytosine deaminase suicide gene therapy with 5-Fluorocytosine treatment on hepatocellular carcinoma cell line HepG2 in vitro and in vivo. Chin Med J (Engl) 128: 1384-1390, 2015.

21. Tsuchiya K, Asahina Y, Matsuda S, Muraoka M, Nakata T, Suzuki Y, Tamaki N, Yasui Y, Suzuki S, Hosokawa T, et al: Changes in plasma vascular endothelial growth factor at 8 weeks after sorafenib administration as predictors of survival for advanced hepatocellular carcinoma. Cancer 120: 229-237, 2014.

22. Sadeghi M, Lahdou I, Oweira H, Daniel V, Terness P, Schmidt J, Weiss KH, Longerich T, Schemmer P, Opelz G and Mehrabi A: Serum levels of chemokines CCL4 and CCL5 in cirrhotic patients indicate the presence of hepatocellular carcinoma. Br J Cancer 113: 756-762, 2015.

23. Qu L, Wang Y, Gong L, Zhu J, Gong R and Si J: Suicide gene therapy for hepatocellular carcinoma cells by surviving promoter-driven expression of the herpes simplex virus thymidine kinase gene. Oncol Rep 29: 1435-1440, 2013.

24. Yu BF, Wu J, Zhang Y, Sung HW, Xie J and Li RK: Ultrasound-targeted HSVtk and Timp3 gene delivery for synergistically enhanced antitumor effects in hepatoma. Cancer Gene Ther 20: 290-297, 2013.

25. Tilghman SM and Belayew A: Transcriptional control of the murine albumin/alpha-fetoprotein locus during development. Proc Natl Acad Sci USA 79: 5254-5257, 1982.

26. Sakai M, Morinaga T, Urano Y, Watanabe K, Wegmann TG and Tamaoki T: The human alpha-fetoprotein gene. Sequence organization and the 5'flanking region. J Biol Chem 260: 5055-5060, 1985.

27. Kanai F, Shiratori Y, Yoshida Y, Wakimoto H, Hamada H, Kanegae Y, Saito I, Nakabayashi H, Tamaoki T, Tanaka T, et al: Gene therapy for alpha-fetoprotein-producing human hepatoma cells by adenovirus-mediated transfer of the herpes simplex virus thymidine kinase gene. Hepatology 23: 1359-1368, 1996.

28. Gerolami R, Uch R, Faivre J, Garcia S, Hardwigsen J, Cardoso J, Mathieu S, Bagnis C, Brechot C and Mannoni P: Herpes simplex virus thymidine kinase-mediated suicide gene therapy for hepatocellular carcinoma using HIV-1-derived lentiviral vectors. J Hepatol 40: 291-297, 2004.

29. Sakai Y, Kaneko S, Nakamoto Y, Kagaya T, Mukaida N and Kobayashi K: Enhanced anti-tumor effects of herpes simplex virus thymidine kinase/ganciclovir system by codelivering monocyte chemoattractant protein-1 in hepatocellular carcinoma. Cancer Gene Ther 8: 695-704, 2001. 